\title{
An Idea for Modelling Exogenous Shocks on Supply Networks Using Petri Nets
}

\author{
by
}

Gilbert Fridgen, Christian Stepanek, Thomas Wolf

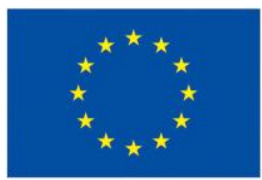

Europäische Union

"Investition in Ihre Zukunft"

Europäischer Fonds für

regionale Entwicklung

Proceedings of the 13th IEEE Conference on Commerce and Enterprise Computing, CEC11, p. 415 


\title{
An Idea for Modelling Exogenous Shocks on Supply Networks Using Petri Nets
}

\author{
Gilbert Fridgen \\ Christian Stepanek \\ Thomas Wolf \\ FIM Research Center, \\ Department of Information Systems Engineering \& Financial Management, \\ University of Augsburg, Germany \\ [gilbert.fridgen|christian.stepanek]@wiwi.uni-augsburg.de \\ thomas.wolf.vwi@googlemail.com
}

\begin{abstract}
Almost all major companies are embedded in complex, global supply networks. Exogenous shocks on these networks (e.g. shortages of natural resources, natural disasters) can indirectly impact companies that are not even aware of their dependencies. This short-paper deals with the idea of modeling and analyzing impacts of exogenous shocks on supply networks using Petri nets. It is especially relevant for high-tech industries (wind and solar energy, besides others) as these are highly dependent e.g. upon rare earth metals. Today, $97 \%$ of the global rare earth metals supply is controlled by China, which is continuously lowering export rates due to own requirements. The final objective of this research stream will be to provide means to simulate and evaluate the vulnerability of companies against exogenous shocks affecting their supply networks.
\end{abstract}

\section{INTRODUCTION}

Today, almost all major companies of the global economic system are embedded in complex supply networks [3]. On the one hand, this bears a lot of advantages (e.g., more flexibility in supplier decisions). On the other hand, these structures increase dynamic interdependencies and therefore a company's exposure to risk: A single incident can have a negative impact on the whole network [10]. Interdependencies are further amplified by permanent optimization measures, taken by companies to face financial pressure and competition, which are besides others caused by globalization [5]. For example, in just in time delivery stock keeping is reduced to a minimum to save cost. This reduces the available buffer and hence increases the temporal dependencies between different entities of the supply networks [14].

Whole supply networks hence become more and more vulnerable regarding the disruption by exogenous shocks, which can be considered in many different manners [13]. An exogenous shock can e.g. represent rapidly rising prices, resource shortages or natural disasters like hurricanes, flash floods or earthquakes. Currently, especially resource shortages are an increasingly important topic, as the elemental limitation connected with the growing demand of emerging markets imposes a serious threat to a resource's availability [9]. Independent of the accurate coverage of specific resources we face an exponential increase of demand and prices in the long run, additionally tightened by the growth and growing wealth of population [2][6].

Especially for resources that are required in small amounts, the general availability is usually more important than their prices. At the moment, we face for example an intensive public discussion about Chinese exports of rare earth metals. Currently more than $97 \%$ of the global supply of rare earth metals is controlled by China [8]. For example, dysprosium and neodymium are used for the production of very strong magnets and hence are essential materials for the production of high tech products like wind power plants or electro engines for automobiles [8]. China recently decided to reduce the export quota on rare earth metals for the first half of 2011 by $35 \%$ in order to build own strategic reserves. Affected manufacturers all over the world face a shortage in rare earth metals or even worse, a disruption in the supply network due to the drop out of resource suppliers or manufacturers on upstream stages of the network [11]. In order to diversify the risk of such disruptions, many manufacturers keep contractual relationships to different suppliers [1]. Suppliers in the context of this paper are considered to be either resource suppliers or manufactures on the different upstream stages of the supply network. However, the lack of information regarding individual dependencies of suppliers on the upstream makes it almost impossible for a single company to identify dependencies it is indirectly exposed to. Hence, it is possible that despite a perceived diversification on the upper stages of the supply network, the indirect dependencies can result in a disruption of the complete supply network exemplarily shown in Fig. 1 [15].

One objective of this research-in-progress is to introduce a feasible approach, to provide entities the necessary information about dependencies and risks, arising from their supply network in order to take adequate actions e.g. recycling, reuse, remanufacturing or substitution of specific critical resources. 


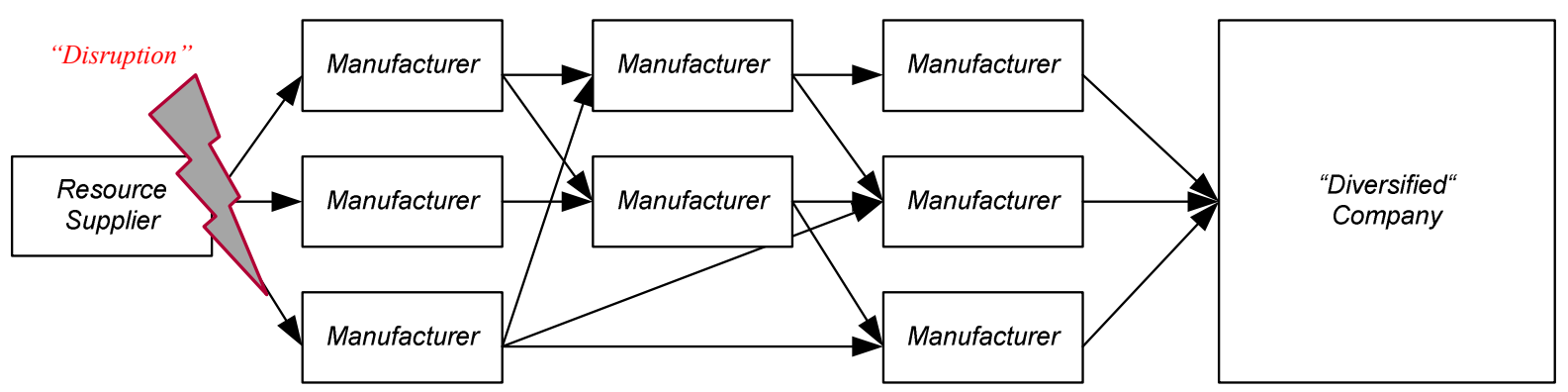

Figure 1 - Diversified Supplier / Manufacturer network depending on one resource supplier

\section{MODELLING APPROACH}

In this paper we consider a modular Petri net $(\mathrm{PN})$ approach to be an appropriate methodology to model Distributed Manufacturer Networks (DMN) [4]. Petri nets enable the modelling of interdependencies. Furthermore it is possible to model exogenous shocks, having several impacts on the different stages of the supply network. As Petri nets are a formal modelling language, they provide the possibility to simulate different states of a system by converting the network into a mathematical equation [12]. Therefore Petri nets not only enable the modelling of dependencies and exogenous shocks, but also allow for calculation of impacts and their effects on dependent entities of the supply network. Moreover the scalability and flexibility of Petri nets offers a great application area. The major disadvantage and hence the reason why Petri nets are not very common in industry, is the rising complexity by trying to model a large supply network [7]. To face this inconvenience we use a modular PN approach assuming that in a high level abstraction a supply network can be illustrated by using four entities, already described by Dotoli and Fanti in 2005 [4].

These entities are resource suppliers, manufacturers, retailers and logistic service providers of which each is illustrated as one module. Each module is depicted by a rectangle and represents the whole Petri net of the specific entity. A module is connected with order and material flows via interfaces located on its borderlines. Incoming and outgoing orders are depicted as interfaces on the top respectively the bottom while interfaces on the left and right hand side represent

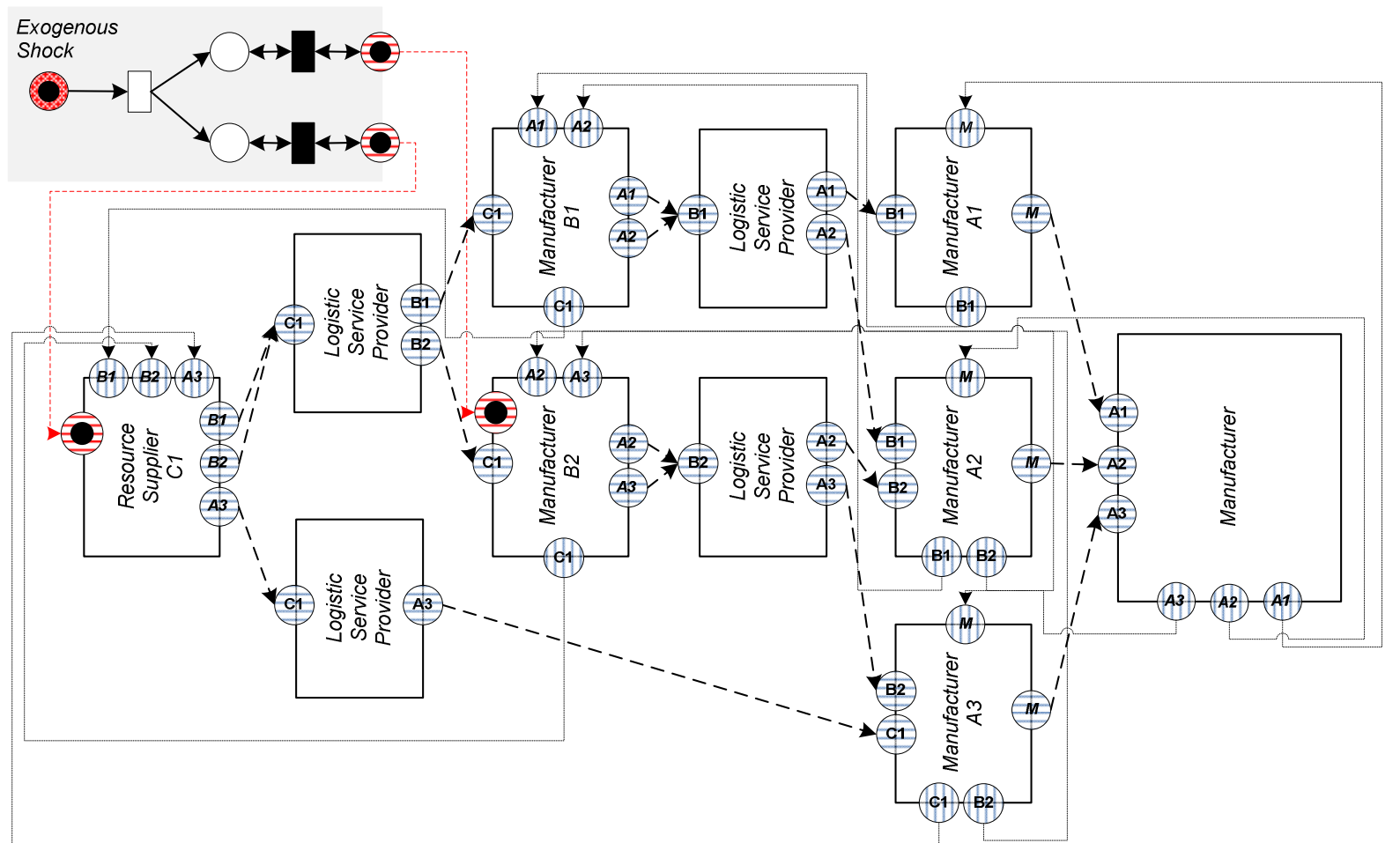

Figure 2 - Exogenous shock in a Distributed Manufacturer Network illustrated with modular Petri nets 
material inflow respectively material outflow. Since the number of incoming orders needs to be consistent with the outflow of material and the outgoing orders with the inflow of material, the number of order interfaces on the top equals the number of material interfaces on the right hand side and the number of order interfaces on the bottom equals the material interfaces on the left. By using a limited number of standardized modules it is possible to reduce the complexity of a PN and at the same time facilitate the application through automatic evaluation [7]. A modularization of Petri nets neither constricts their applicability nor their performance.

Fig. 2 illustrates an exemplary supply network based on the modular PN approach. It is extended by an exogenous shock, which can have different impacts on several entities of the supply network. In this case the supply network has three supply stages $\mathrm{A}, \mathrm{B}$ and $\mathrm{C}$ on the upstream, connected by logistic service providers. The interfaces of the modules refer to the aligned modules on different stages of the supply network.

There are several possibilities to model an exogenous shock, which are still subject to evaluation. In the presented case, the exogenous shock module is based on a timed transition depicted as a white rectangle and immediate transitions depicted as black rectangles. The timed transition ensures an accidental occurrence of a shock while the immediate transitions with their certain attributes represent the connection between the shock and the affected entities. This connection is based on interfaces, which represent input factors for the aligned entities. As to this connection and the algorithm of the attributes, the firing of the immediate transitions is modifying the interfaces in a deteriorating way. Thus the input of the aligned entities is assessed worse than before the shock.

By converting this Petri net-based supply network into a mathematical system, it is possible to quantify the impacts of exogenous shocks on different entities of the supply network, especially the manufacturer at the end of the supply network. However, this paper is still work-in-progress and the detailed calculation is subject of further research.

\section{SUMMARY}

This short-paper introduces an idea to identify and analyze risks, arising from existing interdependencies of a supply network, by using a modular Petri net approach to simulate the impact of exogenous shocks for companies in the supply network. Implementing this approach in a cross-industry system to recognize shortages and price development risks will enable companies to reinforce the whole supply network and to make it less vulnerable to exogenous shocks. Furthermore in terms of return and risk it enables an efficient resource management and creates corporate value more sustainably by coordinating the interplay of complex decentralized decisions [2].

The special emphasis of this short-paper is to identify and measure risks resulting from shortages of rare resources in order to estimate their impacts especially for the renewable energy sector. However this paper is work in progress, the detailed specification of modular Petri nets as well as the simulation and measurement process are subject to further research.

\section{REFERENCES}

[1] Babich, V., Burnetas, N., \& Ritchken, P. (2006). Competition and Diversification Effects in Supply Chains with Supplier Default Risk. Michigan: Industrial and Operations Engineering Department, University of Michigan.

[2] Buhl, H. U., \& Jetter, M. (2009). BISE's Responsibility for our Planet. Business \& Information Systems Engineering, 1 (4), 273-276.

[3] Christopher, M., \& Lee, H. (2004). Mitigating supply chain risk through improved confidence. International Journal of Physical Distribution \& Logistics Management, 34 (5), 388-396.

[4] Dotoli, M., \& Fanti, M. F. (2005). A Generalized Stochastic Petri Net Model for Management of Distributed Manufacturing Systems. Bari: IEEE Dipartimento di Elettrotecnica ed Elettronica.

[5] Harland, C., Brenchley, R., \& Walker, H. (2003). Risk in supply networks. Journal of Purchasing \& Supply Management, 9, 51-62.

[6] Krautkraemer, J. A. (1998). NonrenewableResource Scarcity. Journal of Economic Literature, 36, 2065-2107.

[7] Kindler, E., \& Petrucci, L. (2009). Towards a Standard for Modular Petri Nets: A Formalisation. In G. Franceschinis, \& K. Wolf, Application and Theory of Petri Nets (S. 43-62). Heidelberg: Springer Verlag.

[8] Lewis, M., et al. (2011). A User Guide To Commodities. London: Deutsche Bank AG.

[9] Rosenau-Tornow, D., Buchholz, P., Riemann, A., \& Wagner, M. (2009). Assessing the long-term supply risks for mineral raw materials-a combined evaluation of past and future trends. Resources Policy, 34, 161-175.

[10] Schwarcz, S. L. (2008). Systemic Risk. The Georgetown Law Journal, 97 (1), 193-249.

[11] United Nations Environment Programme, Green Economy Vulnerable to Rare Earth Minerals Shortages, United Nations Environment Programme, 05.01.2011. (Online). Available: http://na.unep.net/geas/science/alert22011_01.php (Accessed: 25.05.2011).

[12] Van der Aalst, W. M., Van Hee, K. M., \& Reijers, H. A. (2000). Analysis of discrete-time stochastic Petri nets. Statistica Neerlandica, 54 (2), 237-255.

[13] Wagner, S. N., \& Neshat, N. (2009). Assessing the vulnerability of supply chains using graph theory. International Journal of Production Economics (126), 121-129.

[14] Waters-Fuller, N. (1995). Just-in-time purchasing and supply: a review of the literature. International Journal of Operations \& Production Management, 15 (9), 220-236.

[15] Wu, T., Blackhurst, J., \& O'Grady, P. (2007). Methodology for supply chain disruption analysis. International Journal of Production Research, 45 (7), 1665-1682. 